\title{
Multi-instrument study of longitudinal wave structures for plasma bubble seeding in the equatorial ionosphere
}

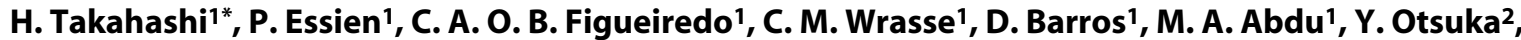 \\ K. Shiokawa ${ }^{2}$, and GuoZhu $\mathrm{Li}^{3}$ \\ ${ }^{1}$ Instituto Nacional de Pesquisas Espaciais, São José dos Campos, Brazil; \\ 2Institute for Space-Earth Environmental Research, Nagoya University, Nagoya, Japan; \\ ${ }^{3}$ Institute of Geology and Geophysics, Chinese Academy of Sciences, Beijing 100029, China
}

\section{Key Points:}

- Large-scale wave structures (LSWSs) of the equatorial ionosphere were observed by detrended TEC mapping.

- The LSWSs had long wavelengths ( 900 km), meridionally extended wave fronts (1600 km), and were propagating mainly NE to SEwards.

- We found that the eastward propagating LSWSs were effective in producing Equatorial Plasma Bubbles.

Citation: Takahashi, H., Essien, P., Figueiredo, C. A. O. B., Wrasse, C. M., Barros, D., Abdu, M. A., Otsuka, Y., Shiokawa, K., and Li, G. Z. (2021). Multi-instrument study of longitudinal wave structures for plasma bubble seeding in the equatorial ionosphere. Earth Planet. Phys., 5(5), 368-377. http://doi.org/10.26464/epp2021047

\begin{abstract}
Large Scale Wave Structures (LSWS) in the equatorial ionospheric F-region were observed by measuring spatial and temporal variations within detrended total electron content (dTEC) data obtained by ground-based GNSS receivers over the South American continent. By using dTEC-maps, we have been able to produce, for the first-time, two-dimensional representations of LSWS. During the period from September to December, the LSWS frequently occurred starting a few hours prior to Equatorial Plasma Bubble (EPB) development. From 17 events of LSWS observed in 2014 and 2015, wave characteristics were obtained: the observed wavelengths, periods, and the phase speeds are respectively, $\sim 900 \mathrm{~km}, \sim 41 \mathrm{~min}$ and $\sim 399 \mathrm{~m} / \mathrm{s}$; the waves propagated from the northeast to southeast. In some cases the front of the oscillation was meridionally aligned, extending to more than $1600 \mathrm{~km}$, the first time such large extension of the wavefront has been reported. From F-layer bottom height oscillation data, measured by ionosonde, LSWS exhibit two different vertical phase propagation modes, in-phase and downward phase. The former mode indicates the presence of a polarization electric field in the F-layer bottom side; the latter suggests propagation of atmospheric gravity waves. The presence of LSWS near the solar terminator, followed by the development of EPBs, suggests that the upwelling of the F-layer bottom height produces a condition favorable to the development of Rayleigh-Taylor instability.
\end{abstract}

Keywords: ionosphere; Equatorial Plasma Bubble; LSWS; TEC

\section{Introduction}

The Earth's equatorial ionosphere exhibits several specific electrodynamic processes. The most outstanding of them are: the equatorial ionization anomaly (EIA) during the day, the Post Sunset Rise (PSSR) of the F-layer, the occurrence of Rayleigh-Taylor instability $(\mathrm{RTI})$, and the generation of Equatorial Plasma Bubbles (EPBs) (Kelley, 2009). Atmospheric gravity waves (AGWs) propagating from below (Röttger, 1973, Vadas et al., 2009) and travelling ionospheric disturbances (TIDs) from other places (Krall et al., 2011) are external forces that disturb the equatorial ionosphere. Especially, in the case of the generation and development of EPBs, there is a precondition to their development: needed is an uplift of the $F$

Correspondence to: H. Takahashi, hisao.takahashi@inpe.br

Received 11 APR 2021; Accepted 13 AUG 2021.

Accepted article online 02 SEP 2021.

(C) 2021 by Earth and Planetary Physics. layer with a drift speed sufficient to produce an instance of RTI. A PSSR occurs under pre-reversal enhancement (PRE) of the zonal electric field along the geomagnetic equator. In addition to the normal mode of PSSR, some additional (electro-dynamical and/or neutral-dynamical) forcing could accelerate or deaccelerate the upwelling, resulting in favorable or un-favorable conditions for generation of an RTI (Abdu et al., 2015). Propagation of atmospheric gravity waves during a PSSR could contribute an additional forcing. Therefore, monitoring such parameters as the equatorial ionosphere's electron density, vertical drift velocity, F-layer peak height, and steepness of its bottom-side height profile, in addition to its dynamical processes, during the afternoon-to-evening hours, is critical to elucidating the conditions of EPB generation and subsequent development.

Large-Scale Wave Structures (hereafter denoted as LSWS) observed during the evening uplift of the ionosphere, and their involvement in the subsequent generation of EPBs, were first dis- 
cussed by Tsunoda (2005). According to him, the longitudinal wave structure with a horizontal wavelength of around $400 \mathrm{~km}$, a period of $\sim 1$ hour, and an eastward phase velocity of $\sim 100 \mathrm{~m} / \mathrm{s}$ was superposed on the evening PSSR. Soon after, Saito and Maruyama (2007) reported the presence of longitudinal differences in the temporal variations of F-layer bottom heights when the equatorial Spread F occurred, suggesting thereby the presence of longitudinal variability of the F layer during the sunset-toevening hours. Thampi et al. (2009) reported observation of an instance of LSWS followed by EPBs from the Communications/Navigation Outage Forecasting System (C/NOFs) satellite data. They observed that the LSWS had horizontal wavelengths of 500$700 \mathrm{~km}$ with an amplitude of oscillation of $\pm 0.4 \mathrm{TECu}$. They also found that the LSWS was formed before the E-region sunset, suggesting that the source of the LSWS was not a PSSR but might be related to E-layer electrodynamics. Narayanan et al. (2012) reported a case study of the presence of small-scale wave structure in addition to LSWS as a pre-requisite to the triggering of EPBs. Ram et al. (2014) studied longitudinal variations of the TEC observed by ground-based receivers and found that longitudinal wave structure were frequently observed before the E-region sunset, of which the horizontal scale of the oscillation were around 200$500 \mathrm{~km}$ and latitudinal extension was of the order of $500-600 \mathrm{~km}$, centered at the geomagnetic equator. The amplitude of the observed oscillation increased toward the night. They also reported that EPBs were observed to occur when the amplitude of the wave oscillation was larger than 2 TECu.

Later, Tsunoda (2015) drew a schematic diagram of LSWS, wherein a meso-scale wave (with a wavelength of a few hundreds of $\mathrm{km}$ ) was propagating on a longer scale $(\sim 1500 \mathrm{~km})$ F-layer uplift (PSSR) prior to the F-layer peak. Tsunoda (2015) further suggested that the meso-scale upwelling has its origin in atmospheric gravity waves from the lower atmosphere, propagating upward into the E-region, producing a polarization electric field, which will fieldline map to the F-region bottom height. Abdu et al. (2015) analyzed ionosonde data from the equatorial region and observed periodic height oscillation at fixed plasma frequencies, followed by Spread-F development during the post sunset hours. They also observed that the oscillation amplitude increased toward the Flayer peak. They found further that there was no activity of Spread $F$ when the oscillation was weak. From the observational evidence, they suggested the presence of a large-scale wave structure in the F-layer bottom height when the RTI developed.

A consensus seems to have emerged that during the PSSR period there could be additional upwelling that triggers an RTI in the Flayer bottomside, generating EPBs (Tsunoda, 2015). The source of that additional upwelling could be atmospheric gravity waves accelerating or decelerating the PSSR. However, how the waves act in the ionosphere to produce the vertical oscillation of the ions that results in development of an RTI in the F-layer is not yet well understood (Tsunoda et al., 2018). It is still an open question whether the upwelling of the F-layer bottom side is due to a polarization electric field generated in the E-layer and its mapping to the $\mathrm{F}$ layer (FAl), or is produced directly by the AGW-induced wind oscillation (Abdu et al., 2015). Further, there is a lack of observational data on the wave characteristics, such as the wavelength, period, phase velocity and the propagation direction, to determ- ine whether the upwelling is due to direct driving by gravity waves, or through E- and F-region electrodynamic coupling.

Another point to be investigated would be the latitudinal extension of the LSWS. Previous observations of the longitudinal wave structures (Li GZ et al., 2012; Patra et al., 2013; Abdu et al., 2015, Liu KK et al., 2019) have revealed that the satellite traces in the ionogram (a signature of LSWS) and airglow wave-like structures preceding the EPBs were observed not only at the equatorial region but also in the low latitudes, even at the dip latitude of $14.3^{\circ} \mathrm{N}$ (Liu KK et al., 2019). However, how the low latitude features were related to the equatorial LSWS has not been clear. The present dTEC observations over South America provide direct evidence that LSWS can extend from the magnetic equator to low latitudes.

The purpose of the present work is, therefore, to investigate the longitudinal structure of the equatorial ionosphere by observing several ionospheric parameters, including GNSS-based TEC, detrended TEC (dTEC), and ionospheric heights at fixed plasma frequencies from ionogram and the airglow atomic oxygen $630 \mathrm{~nm}$ images. From two years of ground-based data over the South American equatorial and low latitude regions $\left(0\right.$ to $\left.20^{\circ} \mathrm{S}\right)$, we could identify 17 cases in which so-called LSWS were followed by development of equatorial plasma bubbles (EPBs). Two such cases are presented here, as typical examples; the relationship between the LSWS and the seeding process of EPBs will be discussed.

\section{Observation}

Observations of spatial and temporal variations of the ionosphere and of the generation and development of EPBs have been carried out using several ground-based instruments. The present study uses data obtained by GNSS ground-based receivers, ionosondes, and airglow imagers.

\subsection{TEC and dTEC}

The ionospheric Total Electron Content (TEC) is obtained from measurement of the phase delay $(\mathrm{d} S)$ of GNSS radio waves in the ionosphere, as given by:

$$
\mathrm{d} S=40.3[\mathrm{TEC}] / f^{2} \quad(\mathrm{~m}),
$$

where " $f$ " is the frequency of the radio wave $\left(s^{-1}\right)$. [TEC] is the total electron content along a column of one $\mathrm{m}^{2}$ area, in the direction of the wave propagation, where 1 TECu corresponds to $1 \times 10^{16}$ electrons $\mathrm{m}^{-2}$. In practice, the phase delay is calculated by using the phase difference between two carrier wave frequencies $f_{1}$ and $f_{2}$. Details of the calculation process have been presented elsewhere (Otsuka et al., 2002, Takahashi et al., 2016). TEC mapping (TECMAP) over South America has been carried out using more than 140 GNSS receivers operated over the continent by several GNSS networks. All of the data are processed and the TECMAPs are produced by the Brazilian Studies and Monitoring of Space Weather (EMBRACE) (http://www2.inpe.br/climaespacial/portal/ en/) since 2012.

Small amplitudes of the TEC variation, less than 1 TECu, and the short period oscillation are obtained by calculating the detrended TEC (dTEC): 


$$
(\mathrm{dTEC})_{t}=(\mathrm{TEC})_{t}-\langle\operatorname{TEC}(t \pm 30 \mathrm{~min})\rangle
$$

where $<>$ indicates an average of the TEC $(t-30 \mathrm{~min})$ to TEC $(t+$ $30 \mathrm{~min}$ ). By this process we can suppress the long-term TEC oscillation (of more than one hour). The dTEC values calculated in this manner are in a range of -1 to +1 TECu variation. According to Figueiredo et al. (2018), the amplitude of oscillation of medium scale travelling ionospheric disturbances (MSTIDs) is of the order of $0.2 \mathrm{TECu}$ and the period of oscillation is less than one hour. Therefore, our present calculation using Equation (2) would be appropriate to determine the ionospheric perturbations prior to and during the solar terminator passage.

The $(\mathrm{dTEC})_{t}$ values obtained from all the combinations of GNSS signals of the ground-based receivers in a selected area at a time " $t$ " can be plotted on a map, producing a dTECmap with a time resolution of 1 minute. The bin size of the dTEC map is $0.30^{\circ} \times$ $0.30^{\circ}$ in latitude and longitude; smoothing ( $5 \times 5$ binning) was then applied, corresponding to a size of $1.5^{\circ} \times 1.5^{\circ}$ latitude and longitude. Therefore, spatial resolution of dTEC on the map is limited to around $150 \mathrm{~km}$. In this way, we can identify the wavelike oscillation of dTEC values with horizontal wavelength equal to or larger than $300 \mathrm{~km}$.

\section{2 lonograms}

Two digital ionosondes (DPS-4) (http://www.digisonde.com/instrument-description.html) have been operated in the equatorial and low latitude regions in Brazil, one at São Luís $\left(2.6^{\circ} \mathrm{S}, 44.2^{\circ} \mathrm{W}\right.$, geomag. lat. $\left.3.9^{\circ} \mathrm{S}\right)$ and the other at Fortaleza $\left(3.9^{\circ} \mathrm{S}, 38.4^{\circ} \mathrm{W}\right.$, geomag. lat. $\left.6^{\circ} \mathrm{S}\right)$. Both are operated at a cadence of 10-min time interval. lonograms and temporal variations of the heights at fixed plasma frequencies are referred to investigate the presence of satellite traces, Spread F, and F-layer bottom height oscillations. lonosonde data used in the present study were obtained from the EMBRACE data center.

\subsection{Airglow $630 \mathrm{~nm}$ Imager}

An airglow all-sky imager for measurement of the oxygen $630 \mathrm{~nm}$ emission has been operated at São João do Cariri $\left(7.4^{\circ} \mathrm{S}, 36.5^{\circ} \mathrm{W}\right.$, geomag. lat. $\left.11.9^{\circ} \mathrm{S}\right)$. The airglow image covers an ionospheric area with a diameter of $\sim 1500 \mathrm{~km}$ at $250 \mathrm{~km}$ altitude where the emission layer is located. The initial phase of the F-layer bottom height oscillation during the evening uplift can be detected by the imager. The data processing of the $630 \mathrm{~nm}$ images has been presented elsewhere (Takahashi et al., 2020).

\section{Results}

We analyzed TEC-maps obtained in 2014 and 2015, focusing on the longitudinal wave structure observed during the evening solar terminator passage. In general, well-formed TEC gradients along the geomagnetic longitude, parallel to the solar terminator line, are observed during the period from September to March. Among them we frequently observed wavelike depletion structures of the TEC. We designated a wave structures as an instance of LSWS if (1) there was a wave propagation structure in the dTEC keograms, (2) there were periodic oscillations in the ionogram fixed frequencies $(5-8 \mathrm{MHz}),(3)$ the structure appeared 0 to 3 hours prior to the passage of the solar terminator at the E-region height and was followed by an EPB occurrence, and (4) it was observed in the latitudinal zone of 0 to $15^{\circ} \mathrm{S}$. The atmospheric condition of geomagnetic activity was not considered. The identification of wave structure and wave characteristics are performed by using dTEC map and its keogram (Takahashi et al., 2020). As mentioned later, we identified a total of 17 cases that met these criteria. Two events, typical of the 17 , are presented in some detail using their TEC map, dTEC map, keogram and F-layer true height oscillation data. All of the keograms and the F-layer $d(h F)$ time series used in the present work are presented in an attached Support file.
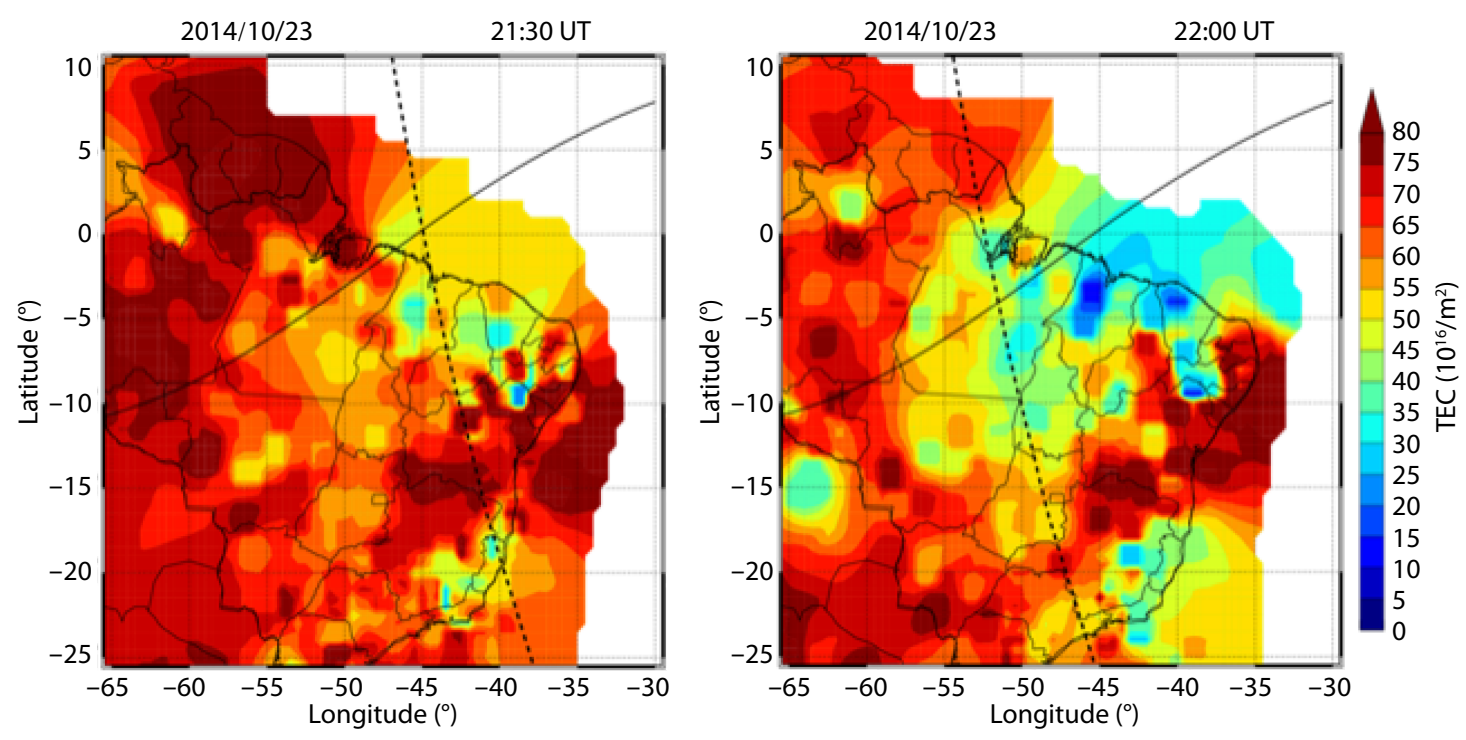

Figure 1. TEC map of the northeastern equatorial region of South America on the evening of 23 October 2014, at 21:30 UT (left panel) and 22:00 UT (right panel). The black line is the geomagnetic equator, and the black dashed line is the location of the solar terminator at $120 \mathrm{~km}$ altitude. 


\subsection{Case 1: 23 October 2014}

Figure 1 shows a TEC-map over the equatorial and low latitude $\left(5^{\circ} \mathrm{S}-25^{\circ} \mathrm{S}\right)$ region of Brazil for the evening of 23 October 2014. The color shade indicates spatial variability of the TEC from 10 (blue) to 80 (red) TECu. The solid black line indicates the geomagnetic equator; the dashed black line indicates the location of the solar terminator at $120 \mathrm{~km}$ altitude (the topside of E-layer). At 21:30 UT (18:30 LT) (left panel), TEC depletions on the west- and east-sides of the terminator can be seen. This sort of depletion does not normally occur. Instead, homogeneous decreases of the TEC are typically observed along the magnetic equator in the evening hours. 30 minutes later at 22:00 UT (right panel), further depletions can be seen along the terminator line, and EPBs were seen to initiate in the eastern side at 40 and $45^{\circ} \mathrm{W}$.

A dTEC-map with an amplitude of \pm 0.2 TECu provides further details of the spatial TEC variability in the evening period. Figure 2 presents a snapshot of the dTEC-map at 21:16 UT. Note that the amplitude of the fraction presented is +0.2 to -0.4 TECU. TEC enhanced belts can be seen along the meridional line, one at $47^{\circ} \mathrm{W}$ (wide) and the other at $38^{\circ} \mathrm{W}$ (weak and narrower). Both crests are indicated by dark blue arrows. The black dash-dot line indicates the solar terminator at $120 \mathrm{~km}$, which is almost parallel to the crests. The extent of the crests is approximately $1000 \mathrm{~km}$; the western crest is located at about $9^{\circ}$ west of the sunset line. It is worth noting that the crests extend to the south by more than $12^{\circ}$, suggesting that the wave front is meridionally extended by more than $1500 \mathrm{~km}$.

The time evolution of the dTEC-map can be seen by making a keogram, a sliced dTEC at latitude $\left(10^{\circ} \mathrm{S}\right)$ and longitude $\left(42.5^{\circ} \mathrm{W}\right)$ as a

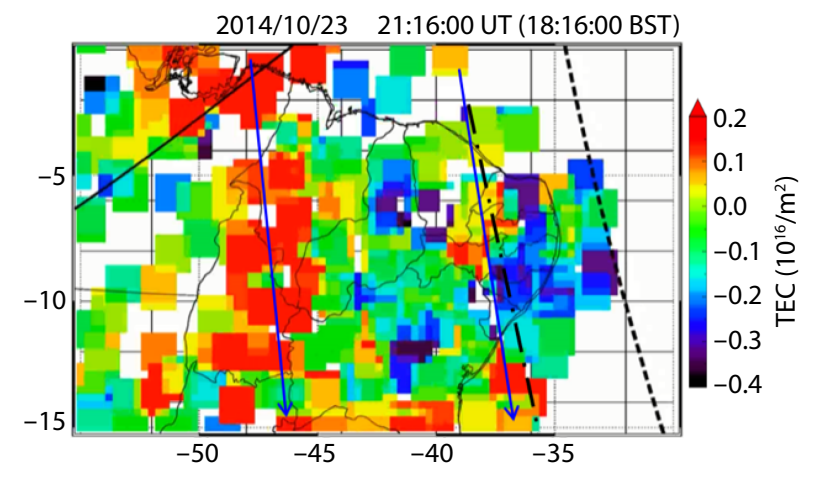

Figure 2. ATEC map of the northeastern region of South America on 23 October 2014 at 21:16 UT (18:16 LT at $\left.45^{\circ} \mathrm{W}\right)$. The black dash-dotted line and black dashed lines indicate the solar terminator line at $120 \mathrm{~km}$ and $300 \mathrm{~km}$, respectively. The blue arrows indicate the dTEC crests.

function of time, which is plotted in Figure 3. The upper panel shows the longitudinal variation $\left(30^{\circ} \mathrm{W}-50^{\circ} \mathrm{W}\right)$ of the dTEC at $10^{\circ} \mathrm{S}$ from 17:00 UT to 24:00 UT. The black dashed line indicates the solar terminator at $300 \mathrm{~km}$ altitude at the latitude of $42.5^{\circ} \mathrm{W}$. Before 22:00 UT, between 20:30 and 21:50 UT (highlighted by a rectangular box by a black line), there is a crest and a trough propagating toward the east. The lower panel presents latitudinal variation $\left(0-15^{\circ} \mathrm{S}\right)$ at $42.5^{\circ} \mathrm{W}$. The two keograms and the movement of the phase verify a latitudinally aligned wave structure propagating toward the east, encountering the solar terminator around 21:50 UT, at $40^{\circ} \mathrm{W}$. The wave characteristics, calculated by Fast Fourier Transform from the keograms, are as follows: the horizontal wavelength is $896.2 \mathrm{~km}$, the period is $43 \mathrm{~min}$, the phase speed is

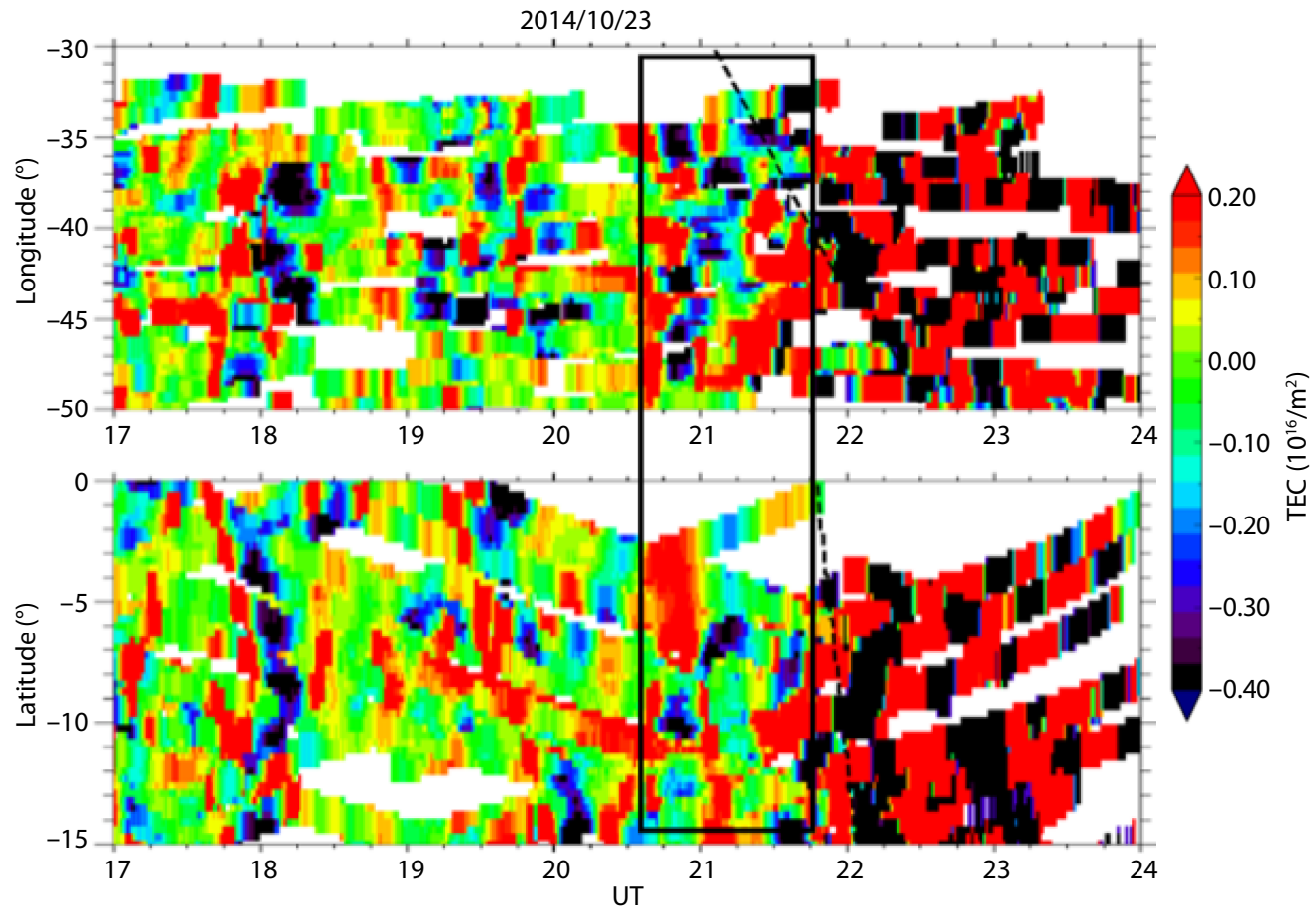

Figure 3. Keogram of dTEC, the longitudinal cut of 30 to $50^{\circ} \mathrm{W}$ at $10^{\circ} \mathrm{S}$ (upper panel) and the latitudinal cut of 0 to $15^{\circ} \mathrm{S}$ (lower panel) at $42.5^{\circ} \mathrm{W}$, from 17:00 to 24:00 UT. The black dashed lines indicate the solar terminator at $300 \mathrm{~km}$ and the black line rectangular box highlights the LSWS propagating time zone. 
$347.4 \mathrm{~m} / \mathrm{s}$, and the propagation direction is $90.1^{\circ}$ from north, that is to the eastward. After 22:00 UT the dTEC perturbation increased to values much larger than $\pm 1 \mathrm{TECu}$, due to the development of an EPB, as can be seen in Figure 1.

On this same evening (23 October 2014), an airglow imager operated at São João do Cariri $\left(7.5^{\circ} \mathrm{S}, 36.5^{\circ} \mathrm{W}\right)$ observed a depletion in the $630 \mathrm{~nm}$ emission rates caused by the beginning phase of an EPB development. The depletion started at 22:00 UT and extended to the south at 22:30 UT. The ionosonde at Fortaleza $\left(3.9^{\circ} \mathrm{S}\right.$, $38.4^{\circ} \mathrm{W}$ ) observed F-layer bottom side oscillations (satellite traces) at 21:50 UT, that were followed by Spread-F development starting at 22:00 UT. Temporal evolutions of the real heights at the fixed plasma frequencies 5, 6, 7 and $8 \mathrm{MHz}$, are presented in Figure 4. The PSSR started at around 18:30 UT and the layer height peaked at 22:00 UT. During the course of uplift, the layer oscillated at least twice, first at 20:00 UT and then again at 21:00 UT. The band-pass filtered oscillations, $d(h F)$, shown in the figure, indicate that the four frequencies oscillated in phase without any
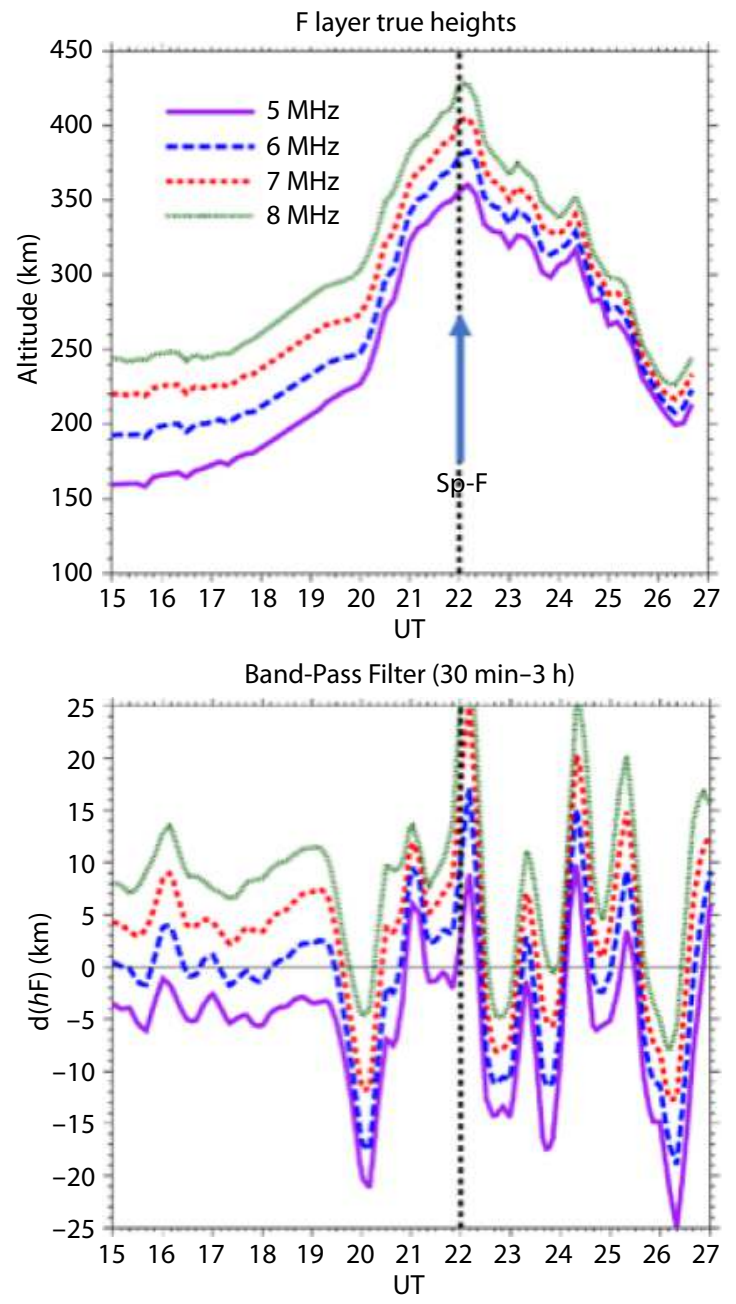

Figure 4. Temporal variations of the F-layer true height $(h \mathrm{~F})$ at fixed plasma frequency of 5 to $8 \mathrm{MHz}$ from 18:00 UT (15:00 LT) to 27:00 UT (24:00 LT) on 23 October 2014: for true height (upper panel) and differential, $d(h F)$, (lower panel). The vertical dashed line indicates the moment of solar terminator passage at $300 \mathrm{~km}$ altitude. The arrow (upper panel) indicates the moment of Spread-F occurrence. time lag between them, suggesting that the oscillations were not directly due to the passage of atmospheric gravity waves, but due instead to electrodynamic forcing from below (Abdu et al., 2015).

From the observational evidence of the spatial and temporal oscillation of the dTEC, ionogram, and airglow images, we conclude that during these afternoon-to-evening hours, from 18:00 to 22:00 UT (15:00 to $19: 00 \mathrm{LT}$ at $45^{\circ} \mathrm{W}$ ), bottom height oscillation of the Flayer took place in the course of the PSSR. The oscillations, propagating eastward, presented a horizontal wavelength of $\sim 900 \mathrm{~km}$, for a period of $\sim 40$ minutes, and a horizontal phase speed of $\sim 350 \mathrm{~m} / \mathrm{s}$. The amplitude of oscillations of the dTEC was approximately $0.5 \mathrm{TECu}$, and the EPB developed at around 22:00 UT.

\subsection{Case 2: 02 November 2015}

Figure 5 presents another example of a TEC-map, this one for the evening of 02 November 2015. The black dashed line indicates the location of the solar terminator at $120 \mathrm{~km}$ at the time of the TEC mapping. In the left panel (21:40 UT), one can see a gradual decrease of the TEC to the east of the terminator. The gradient seems to be parallel to the terminator line, showing some zonally oscillating structure. It can be seen that the plasma density started to decrease when the sunset reached the E-region height $(\sim 110 \mathrm{~km})$. The right panel of Figure 5 shows the TEC-map at 22:20 UT, 40 min later than in the left panel. The solar terminator advanced to the west, generating plasma depletions. Three plasma bubbles (EPBs) can be seen behind the terminator at the equator, at $50^{\circ} \mathrm{W}, 43^{\circ} \mathrm{W}$ and $37^{\circ} \mathrm{W}$. During the period of November to February, the solar terminator line becomes almost parallel to the geomagnetic meridian in the eastern side of the South American Equatorial region, which makes the $E$ layer act more effectively in causing F-layer uplift (PRE) (Kelley, 2009).

The dTEC maps in Figure 6 present further details of the plasma depletions around the solar terminator. In the upper panel (21:36 UT) one can see a crest and a trough of the dTEC at roughly $37^{\circ} \mathrm{W}-40^{\circ} \mathrm{W}$ and $7^{\circ} \mathrm{S}$. The amplitude of the oscillation was much larger than $0.2 \mathrm{TECu}$. The solar terminator at $300 \mathrm{~km}$ altitude (broken line) was overlaid on the crest. Six minutes later (middle panel), the solar terminator advanced westwards by $160 \mathrm{~km}$, but the displacement of the crest was negligible, and another crest formed at around $40^{\circ} \mathrm{W}-42^{\circ} \mathrm{W}$. The distance between the crests is approximately $550 \pm 100 \mathrm{~km}$. At 21:50 UT (lower panel) the crest behind the terminator was superposed by disturbed dTECs, which seems to signal the beginning of evolution of the EPBs. The amplitude of oscillations obtained in this case was almost $\pm 1 \mathrm{TECu}$, which is higher than those normally observed $( \pm 0.2 \mathrm{TECu})$ in the MSTIDs (Figueiredo et al., 2018). It is worth noting that the latitudinal extension of the waves was more than $15^{\circ}(1600 \mathrm{~km})$.

On this evening, an airglow $630 \mathrm{~nm}$ imager at Cariri $\left(7.6^{\circ} \mathrm{S}, 36.5^{\circ} \mathrm{W}\right)$ observed a depletion starting at around 21:40 UT (18:40 LT). Figure 7 shows the geographically coordinated OI $630 \mathrm{~nm}$ image observed at 21:43 UT. A depression of the emission intensity can be observed over the zenith (upper panel), which indicates vertical oscillation of the F-layer bottomside, indicating an initial phase of EPB seeding. Ten minutes later (lower panel) the depletion had extended to the south, forming an EPB structure. Comparing the 

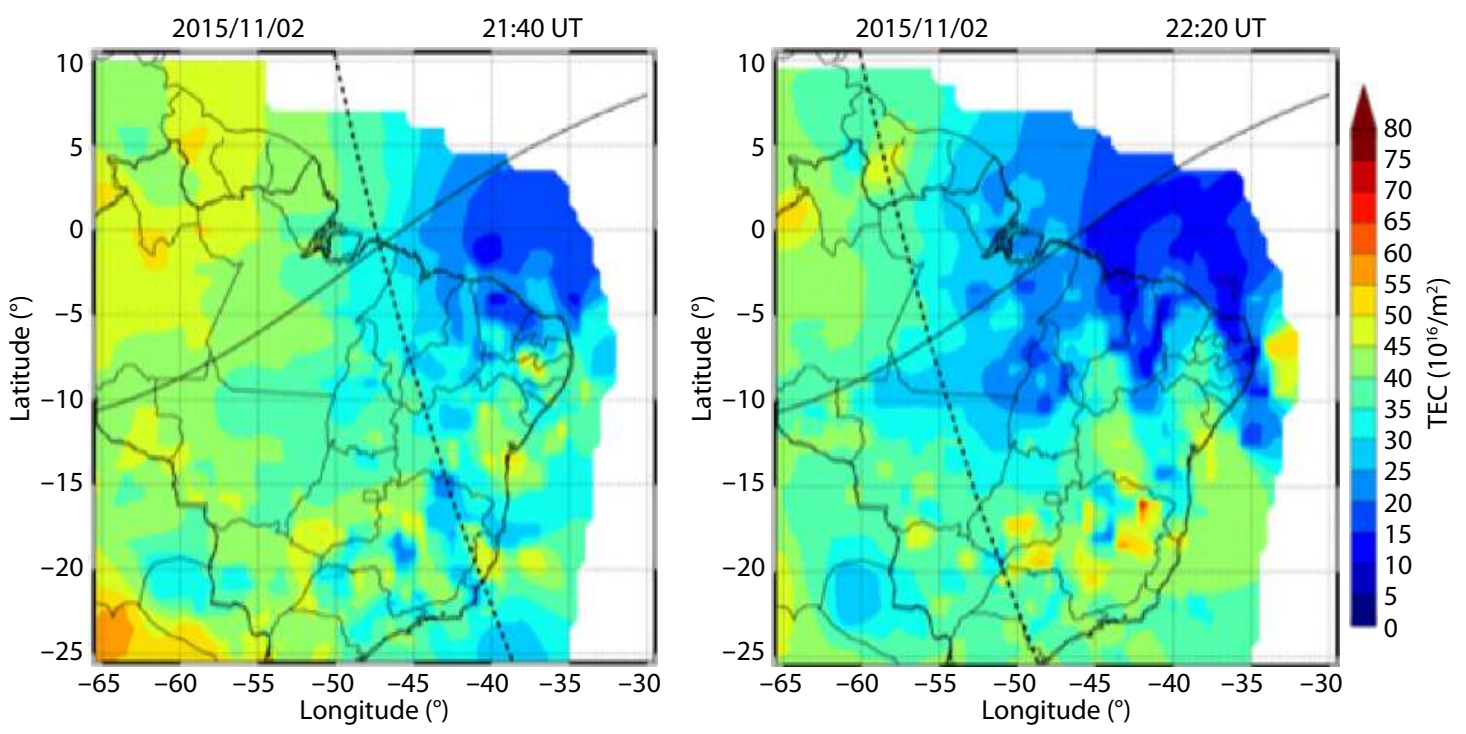

Figure 5. TEC map on the evening of 02 November 2015, at 21:40 UT (left panel) and 22:20 UT (right panel). The black full line is the geomagnetic equator, and the black dashed line is the location of the solar terminator at $120 \mathrm{~km}$ altitude.

dTEC-maps of Figure 6 (middle panel) and Figure 7 (upper panel), which present nearly simultaneous observations, it appears that when the dTEC was positive (at around the $36^{\circ} \mathrm{W}$ line) the $630 \mathrm{~nm}$ emission rate was low, indicating that the emission height was higher.

The ionosonde at Fortaleza $\left(3.9^{\circ} \mathrm{S}, 38.4^{\circ} \mathrm{W}\right)$ observed satellite traces in the ionogram taken at 21:30 UT and subsequently the Spread F started at 21:50 UT. Figure 8 (upper panel) depicts the temporal evolution of the F-layer height at fixed plasma frequencies of 5, 6, 7, and $8 \mathrm{MHz}$. The vertical dashed line indicates the solar terminator at $300 \mathrm{~km}$ over Fortaleza. The F-layer rose to above $400 \mathrm{~km}$ due to the strong PSSR, and reached its maximum height at around 22:00 UT. The Spread F appears to have occurred 10 to 15 minutes before the F-layer's 22:00 UT peak height. The $630 \mathrm{~nm}$ images and ionosonde data indicate that the F-layer over the $36^{\circ} \mathrm{W}-38^{\circ} \mathrm{W}$ zone started to become unstable at 21:30 UT, leading to the development of Spread F as indicated by the onset of EPBs at 21: 50 UT. It is significant that in Figure 8 (lower panel), there are temporal oscillations of the heights at $5-8 \mathrm{MHz}$ between 19:00 to 20:00 UT, and that they are almost in phase, suggesting that these height oscillations might originate from the local electric field, as suggested by Abdu et al. (2015). Therefore, the strong uplifting observed might reflect a contribution from the longitudinal waves also observed, the so called LSWS.

In the case of the 02 November 2015 event, we observed a wavelike structure of the TEC, the wave front being parallel to the solar terminator line, resulting in bottom-side height oscillation during the evening PSSR. The horizontal wavelength was around $550 \mathrm{~km}$, and the amplitude of the oscillation of the TEC was approximately 1.0 TECu, which is larger than what is expected in typical cases of MSTID (Figueiredo et al., 2018).

\section{Discussion}

From the dTEC observational results presented here for 23 October 2014 and 02 November 2015, we conclude that there are fre- quent occurrences of periodic oscillations of the F-layer bottom height and appearances of wave front of the dTEC during the post sunset rise (PSSR) of the F-layer, which result in the development of EPBs. Abdu et al. (2015) has presented such oscillation structures of the F-layer at fixed plasma frequencies and suggested the presence of LSWS superposed on PSSR. Our results presented here are similar to those reported previously by Ram et al. (2014) and Abdu et al. (2015). However, knowledge remains limited of such wave characteristics as the longitudinal and latitudinal extension of the waves, and especially of the relationship between wave fronts and the solar terminator. It is still an open question whether LSWS generation is due to directly to atmospheric gravity waves or due to the polarization electric field generated by gravity wave oscillations in the E-region, or to a dynamical process generated by the solar terminator (Forbes et al., 2008). The present results could provide some clarification of some of the unknown features of the LSWS.

In summary: From two years (2014 and 2015) of TEC data, a total of 730 days of data, we could identify 17 cases in which dTEC keograms indicated wavelike structure near the solar terminator, followed by EPB occurrence. In these cases, the oscillations occurred 0 to 3 hours prior to the solar terminator's crossing at the E-region (110 km). Takahashi et al. (2018) has reported similar observations (35 cases) of same-day occurrence of MSTID and EPBs, collected from a wide latitudinal range $\left(0\right.$ to $\left.35^{\circ} \mathrm{S}\right)$, including the MSTID source region up to the mid-latitude. Our data, however, focused on MSTIDs in the equatorial to low latitude $\left(0^{\circ} \mathrm{S}-15^{\circ} \mathrm{S}\right)$ region, as mentioned above. In Table 1 summarizes the wave characteristics of the events presented here, which are cases in which both LSWS and EPBs were observed on the same day. As reported by Takahashi et al. (2018) the occurrence rate of MSTIDs in this region is high during the winter months (June-July) and the occurrence rate of EPBs is high during the summer (October to January) (Barros et al., 2018). Therefore, the same-day occurrence of LSWS (MSTID) and EPB is observed primarily during the period of September to December, as can be seen in Table 1. 

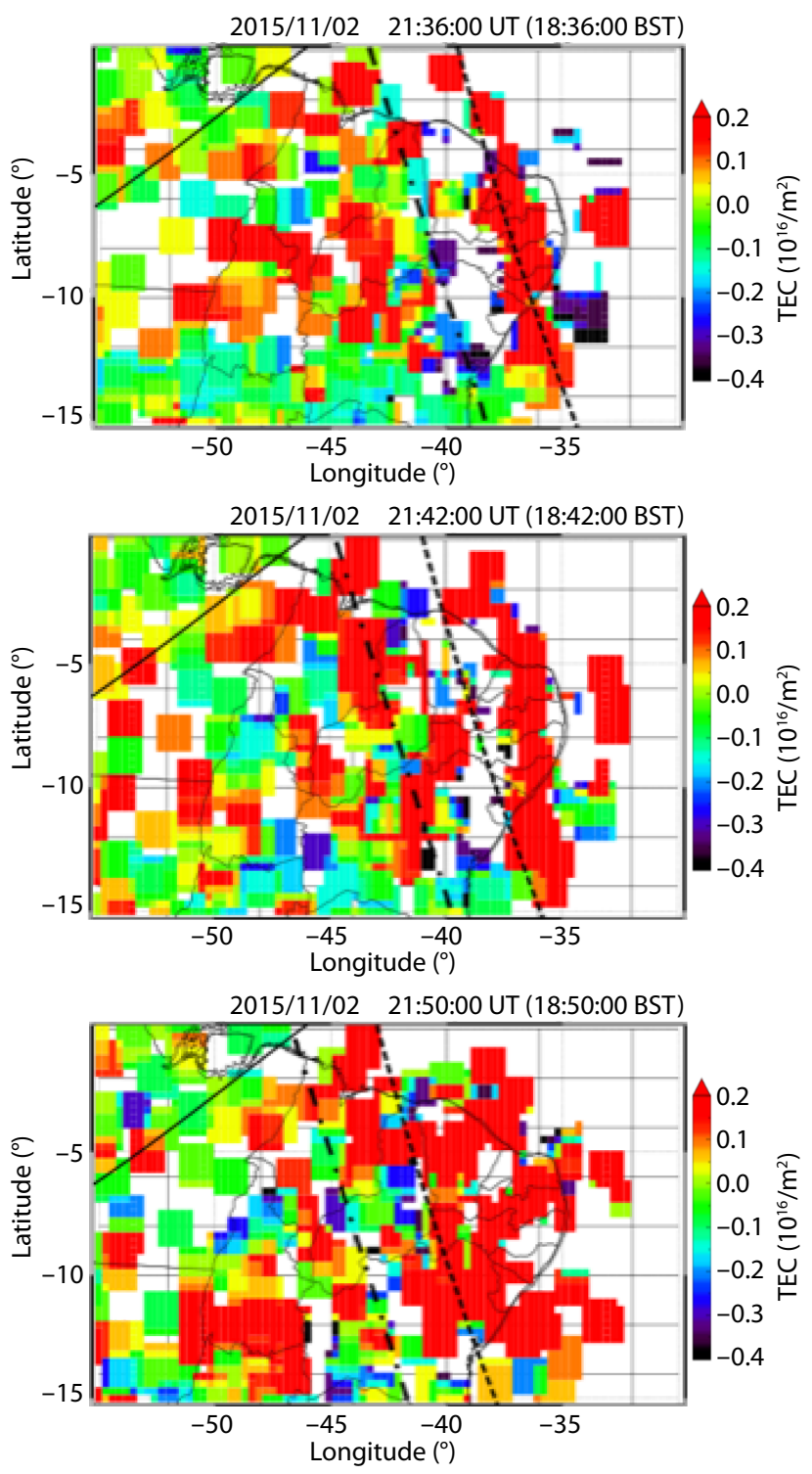

Figure 6. dTEC map of the northeastern region of South America on 02 November 2015 at 21:36 UT (upper panel), 21:42 UT (middle panel) and 21:50 UT (lower panel). The black dash-dot line and dashed line indicate the solar terminator line at $120 \mathrm{~km}$ and $300 \mathrm{~km}$, respectively.

Table 1 reveals that the mean horizontal wavelength is $900 \pm$ $224 \mathrm{~km}$, the period is $41 \pm 16 \mathrm{~min}$, and the phase speed is $399 \pm$ $140 \mathrm{~m} / \mathrm{s}$. Previous studies have reported horizontal wavelengths between 100-700 km (Ram et al., 2014), periods of $60 \mathrm{~min}$, and the eastward phase speeds of $100 \mathrm{~m} / \mathrm{s}$ (Tsunoda et al., 2018). Our present results indicate that the horizontal wavelength and the phase speeds are larger than previously reported. Regarding the amplitude of oscillation in the TEC observation, Thampi et al. (2009) reported that it was 0.4 TECu. In our present observation, it is around 0.1 to $0.5 \mathrm{TECu}$, corroborating the previous data. Tsunoda and White (1981) found that LSWS produces vertical oscillation of the F-layer bottomside, with amplitude of approximately 10 to $30 \mathrm{~km}$. From our present observations of TEC and dTEC mapping, it is not possible to determine whether the dTEC perturbation came from the bottomside or the F-layer peak region. However, the periodic oscillations of the ionosonde fixed fre-
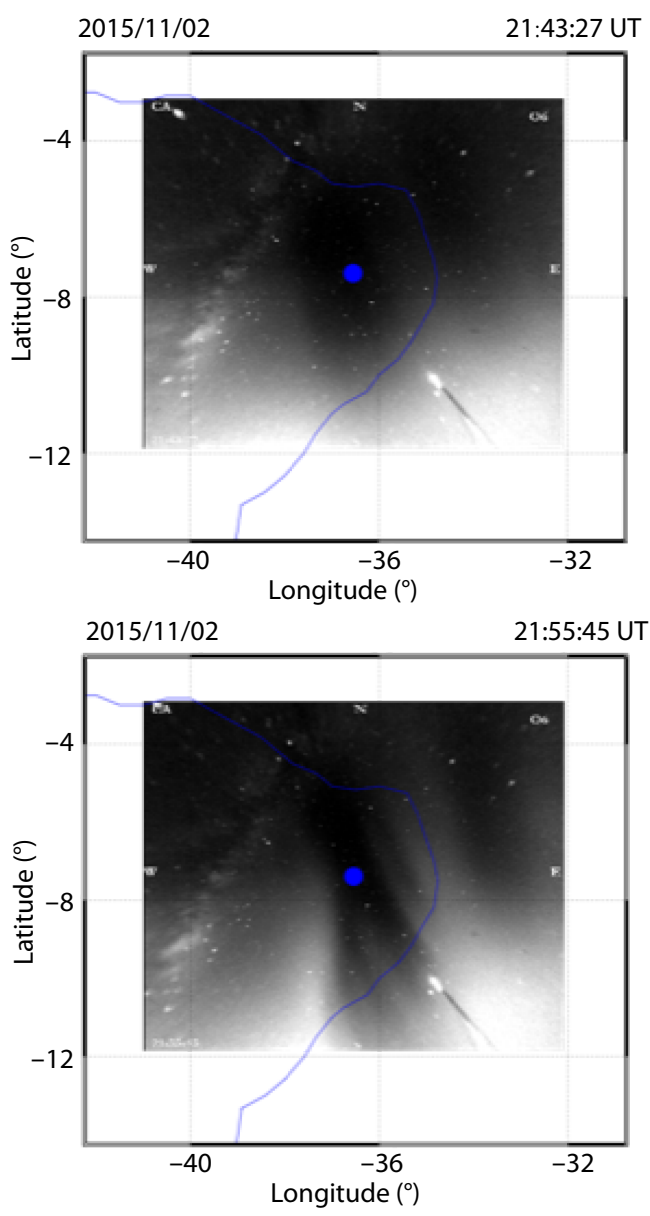

Figure 7. Airglow OI $630 \mathrm{~nm}$ all sky images (flat-field) taken at Cariri observatory $\left(7.5^{\circ} \mathrm{S}, 36^{\circ} \mathrm{W}\right)$ on 02 November, 2015 , at 21:43 UT (18:43 LT) (upper panel) and 21:55 UT(18:55 LT) (lower panel). The blue dot is the location of observatory.

quency true heights, shown in Figures 4 and 8, indicate that the Flayer bottomside was oscillated with an amplitude of around $5 \mathrm{~km}$. The observed wave-like depletion of the Ol $630 \mathrm{~nm}$ emission images shown in Figure 7 (upper panel) also indicates height oscillation of the F-layer bottomside. Therefore, we assume that the observed dTEC wave structures are a signature of the F-layer bottomside oscillation.

The horizontal wavelengths of the selected events are fairly long, being around $900 \mathrm{~km}$ on an average and varying between 700 to $1100 \mathrm{~km}$, and their period was around $40 \mathrm{~min}$. Essien (2020) analyzed MSTIDs in the equatorial and low latitude region of South America during the same period 2014-2015, and found that these MSTIDs were observed primarily during the daytime (09:00-19:00 LT) and their horizontal wavelengths, periods, and phase velocities were, respectively, $650 \pm 150 \mathrm{~km}, 35 \pm 10 \mathrm{~min}$, and $290 \pm 90$ $\mathrm{m} / \mathrm{s}$. We report somewhat longer wavelengths. The phase velocity and the direction of propagation data are summarized in Figure 9. It is interesting to note that the phase velocities are quite variable - from 140 to $640 \mathrm{~m} / \mathrm{s}$ with an average of $399 \pm 140 \mathrm{~m} / \mathrm{s}$. The direction of propagation is anisotropic, with more than $65 \%$ of events propagating toward northeast, east, and southeast. These findings differ from those reported by Essien (2020) whose 

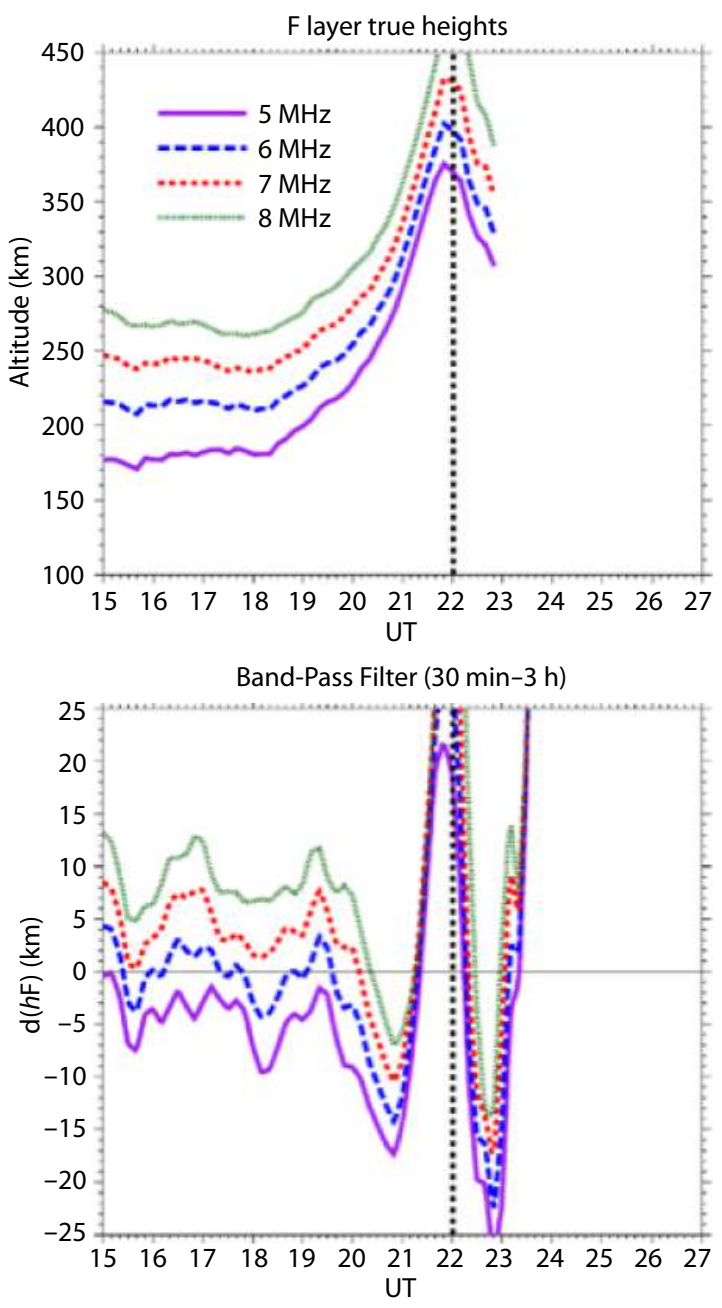

Figure 8. Temporal variations of the $\mathrm{F}$ layer true height $(h \mathrm{~F})$ at fixed plasma frequency of 5 to $8 \mathrm{MHz}$ from 15:00 UT (12:00 LT) to 27:00 UT (24:00 LT) of 02 November 2015: for true height (upper panel) and differential, $d(h F)$, (lower panel). The dotted line indicates the moment of solar terminator pass at $300 \mathrm{~km}$ altitude.

observed the direction to be mainly toward the north and southeast. Our results suggest that the waves propagating toward northeast to southeast during the evening uplift period were more effective in generating R-T instability; these results corroborate those of Tulasi Ram et al. (2014), who demonstrated that the waves propagating eastward in the ionosphere will be more effective in triggering EPBs. We could not find in the data we examined any clear difference in the characteristics between the MSTIDs and the LSWSs. It seems that some portion of MSTIDs propagating eastward are acting as LSWS and generating EPBs.

With regard to horizontal extension of the LSWS wave fronts, the present two cases (Figure 2 and Figure 6) show meridional extension longer than $15^{\circ}(\sim 1600 \mathrm{~km})$. Liu KK et al. (2019) observed such wave structures in the Ol $630 \mathrm{~nm}$ images over Fuke $\left(19.3^{\circ} \mathrm{N}\right.$, $109.1^{\circ} \mathrm{E}$, dip lat. $14.3^{\circ} \mathrm{N}$ ). It appears that the typical LSWS has a long latitudinal extension, from the geomagnetic equator to the low latitude region. The long meridional extension of the wavefronts could be related to the waves driven by the solar terminator. According to Forbes et al. (2008) and Liu HX et al. (2009), the west-

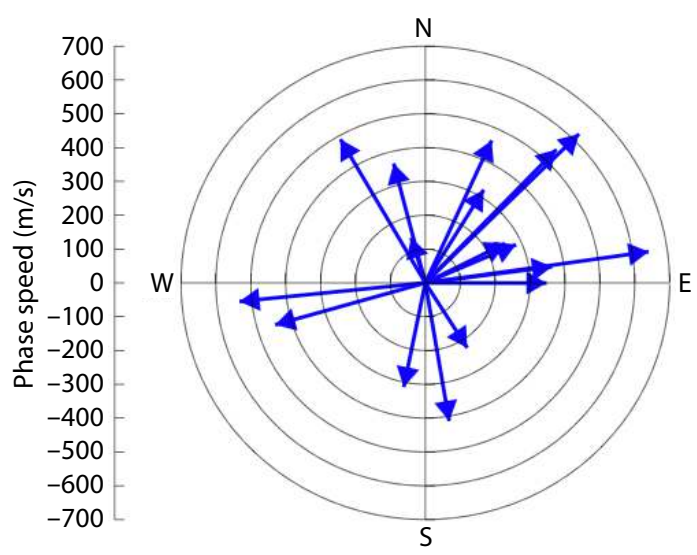

Figure 9. Phase speed and direction of propagation of 17 events of LSWS (in 2014-2015) calculated from keogram, 0-3 hours prior to the solar terminator passage at the E-region height.

ward movement of the solar terminator produces oscillations of atmospheric density and winds, the wavelengths of which are roughly $3000-5000 \mathrm{~km}$ and with wavefronts extending longitudinally with an inclination of around $30^{\circ}$ against the solar terminator line. Our present wave characteristic results, however, are different from those of such solar-terminator-driven waves.

As presented in Figure 4 and Figure 8, the temporal variations of the $\mathrm{d}(h \mathrm{~h})$ at fixed plasma frequencies $(5-8 \mathrm{MHz})$ reveal the oscillations to be in-phase, i.e., with no phase-shift among the different frequencies. This indicates that these oscillations are due to the local polarization electric field in the F-layer bottom height. As Tsunoda (2015) suggested, upward propagating gravity waves generate the polarization electric field in the E-layer that will fieldline-map to the F-layer, generating in-phase oscillation of the Flayer bottom height. In this case the LSWS will appear before the E-region sunset. As mentioned above, the observed dTEC wave structure and $\mathrm{d}(h \mathrm{~F})$ oscillations did appear 0 to 3 hours before the E-region sunset. On the other hand, in the 17 events of LSWS presented in Table 1, there are several cases in which downward phase propagation was observed. These cases might be due to direct perturbation (vertical oscillation) of the neutral atmosphere, produced by the passage of gravity waves in the lower thermosphere and the resulting vertical oscillation of the F-layer bottomside. Takahashi et al. (2020) reported the case of 16 September 2015 when the phase was propagating downward. Whether the LSWS oscillation mode is in-phase or downward-phase propagation mode would depend on the wave generation mechanism, as pointed out by Abdu et al. (2015). To understand better the nature of wave propagation in the ionosphere, further model simulation will be required.

\section{Conclusion}

The characteristics of afternoon-to-evening large-scale wave structures (LSWS) in the equatorial ionosphere were studied from measurements of GNSS-based TEC, ionospheric heights at specific plasma frequencies as read from ionograms, and airglow OI $630 \mathrm{~nm}$ all-sky images. From the analysis of two years (20142015) of these data, 17 LSWS events were selected; their average 
Table 1. Large Scale Wave Structures (LSWS) close to the solar terminator line at around $40^{\circ} \mathrm{W}$ in 2014 and 2015.

\begin{tabular}{|c|c|c|c|c|c|c|c|c|c|c|c|}
\hline Year & Month & Day & Hours (UT) & $\begin{array}{l}\mathrm{HWL} \\
(\mathrm{km})\end{array}$ & $\begin{array}{l}\text { Sigma } \\
(\mathrm{km})\end{array}$ & $\begin{array}{l}\text { Period } \\
\text { (min) }\end{array}$ & $\begin{array}{l}\text { Sigma } \\
\text { (min) }\end{array}$ & $\begin{array}{l}c(H) \\
(\mathrm{m} / \mathrm{s})\end{array}$ & $\begin{array}{l}\text { Sigma } \\
(\mathrm{m} / \mathrm{s})\end{array}$ & $\begin{array}{l}\text { Direction } \\
\left(0^{\circ}-360^{\circ}\right)\end{array}$ & $\begin{array}{c}\text { Sigma } \\
\left({ }^{\circ}\right)\end{array}$ \\
\hline & 3 & 4 & $21-22$ & 873 & 70 & 32,5 & 1,6 & 447,7 & 42,3 & 253,9 & 17,2 \\
\hline & 9 & 12 & $20-21$ & 732,9 & 59,7 & 33,5 & 1,7 & 364,7 & 34,8 & 345,6 & 19,3 \\
\hline & 9 & 17 & $20-21$ & 1111,6 & 71,1 & 34 & 17 & 544,9 & 44,2 & 43,6 & 5,5 \\
\hline \multirow[t]{5}{*}{2014} & 10 & 22 & $21: 30-22: 40$ & 1039,7 & 76,9 & 37,5 & 1,9 & 462,1 & 41,2 & 24,3 & 11,1 \\
\hline & 10 & 23 & $20: 30-21: 40$ & 896,2 & 95,4 & 43 & 2,2 & 347,4 & 40,9 & 90,1 & 0 \\
\hline & 11 & 9 & $20: 45-22: 00$ & 758,4 & 74,7 & 34,5 & 1,7 & 366,4 & 40,5 & 82,5 & 1 \\
\hline & 12 & 6 & $21-22$ & 974,2 & 83,5 & 30,3 & 1,5 & 535,3 & 53,1 & 264,1 & 47,3 \\
\hline & 11 & 1 & $21-22$ & 1454,4 & 127,1 & 37,5 & 1,9 & 646,4 & 65,1 & 81,8 & 1 \\
\hline \multirow[t]{4}{*}{2015} & 11 & 2 & $20-21$ & 844,7 & 67,3 & 101 & 5,1 & 139,4 & 13,1 & 343,1 & 16,4 \\
\hline & 11 & 11 & $21-22$ & 639 & 47,2 & 41,5 & 2,1 & 256,6 & 22,9 & 63 & 3,1 \\
\hline & 11 & 12 & $21-22$ & 715,1 & 56,5 & 42 & 2,1 & 283,8 & 26,5 & 66,5 & 2,7 \\
\hline & 11 & 13 & $17: 00-18: 40$ & 1108,4 & 68,4 & 29,7 & 1,5 & 622,7 & 49,5 & 45 & 5,3 \\
\hline Mean & & & & 899,6 & & 40,8 & & 399,1 & & 151,5 & \\
\hline STD div & & & & 224,5 & & 16,1 & & 140,2 & & 115,5 & \\
\hline
\end{tabular}

Notes: HWL: horizontal wavelength, $c(H)$ : horizontal phase speed, Direction: direction of wave propagation from north at $0^{\circ}$, Sigma: error range.

wavelengths, periods, and phase speeds are found, respectively, to be $900 \pm 224 \mathrm{~km}, 41 \pm 16 \mathrm{~min}$, and $399 \pm 140 \mathrm{~m} / \mathrm{s}$. The LSWS wave fronts were found to be aligned with the solar terminator, extending longer than $1600 \mathrm{~km}$. The propagation direction was mainly toward northeast to southeast, suggesting effectiveness of LSWS in seeding EPBs. We find also that the occurrence of LSWS followed by EPBs is frequent during the September to December period, from which we conclude that effectiveness in triggering EPBs must be due to seasonal variations in LSWS occurrence. The LSWS could be a part of the MSTIDs. We observed two types of vertical oscillation of F-layer bottom heights, in-phase oscillation and downward-phase propagation mode. The former may be due to oscillation of the local polarization electric field; the latter may be generated by local atmospheric gravity waves.

\section{Acknowledgments}

The present work was supported by CNPq (Conselho Nacional de Pesquisa e desenvolvimento) under the grant, 310927/2020-0. C A O B Figueiredo thanks the São Paulo Research Foundation (FAPESP) for its grant 2018/09066-8, and CAPES (Coordenação de Aperfeiçoamento de Pessoal de Nível Superior). Shiokawa and Y. Otsuka also thank the JSPS (Japan Society for Promotion of Science) KAKENHI for its support (grant JP 15H05815). Guozhu Li thanks the National Natural Science Foundation of China for its support (Grant No. 42020104002).

Data availability: TEC-maps, ionosonde data, and airglow image data are available at the EMBRACE data center website: (http:// www2.inpe.br/climaespacial/portal/en/\#).

\section{References}

Abdu, M. A., de Souza, J. R., Kherani, E. A., Batista, I. S., MacDougall, J. W., and Sobral, J. H. A. (2015). Wave structure and polarization electric field development in the bottomside $F$ layer leading to postsunset equatorial spread F. J. Geophys. Res.: Space Phys., 120(8), 6930-6940. https://doi.org/10.1002/2015JA021235

Barros, D., Takahashi, H., Wrasse, C. M., and Figueiredo, C. A. O. B. (2018). Characteristics of equatorial plasma bubbles observed by TEC map based on ground-based GNSS receivers over South America. Ann. Geophys., 36(1), 91-100. https://doi.org/10.5194/angeo-36-91-2018

Essien, P. (2020). Study on medium-scale traveling ionospheric disturbances observed in the South American equatorial region. PhD thesis. INPE.

Figueiredo, C. A. O. B., Takahashi, H., Wrasse, C. M., Otsuka, Y., Shiokawa, K., and Barros, D. (2018). Medium scale traveling ionospheric disturbances observed by detrended total electron content maps over Brazil. J. Geophys. Res.: Space Phys., 123(3), 2215-2227. https://doi.org/10.1002/2017JA025021

Forbes, J. M., Bruinsma, S. L., Miyoshi, Y., and Fujiwara, H. (2008). A solar terminator wave in thermosphere neutral densities measured by the CHAMP satellite. Geophys. Res. Lett., 35(14), L14802. https://doi.org/10.1029/2008GL034075

Kelley, M. C. (2009). The Earth's lonosphere: Plasma Physics and Electrodynamics. International Geophysics Series 96 (2nd ed). San Diego, CA, USA: Academic Press.

Krall, J., Huba, J. D., Ossakow, S. L., Joyce, G., Makela, J. J., Miller, E. S., and Kelley, M. C. (2011). Modeling of equatorial plasma bubbles triggered by nonequatorial traveling ionospheric disturbances. Geophys. Res. Lett., 38(8), L08103. https://doi.org/10.1029/2011GL046890

Li, G. Z., Ning, B. Q., Abdu, M. A., Wan, W. X., and Hu, L. H. (2012). Precursor 
signatures and evolution of post-sunset equatorial spread-F observed over Sanya. J. Geophys. Res., 117(A8), A08321.

https://doi.org/10.1029/2012JA017820

Liu, H. X., Lühr, H., and Watanabe, S. (2009). A solar terminator wave in thermospheric wind and density simultaneously observed by CHAMP. Geophys. Res. Lett., 36(10), L10109. https://doi.org/10.1029/2009GL038165

Liu, K. K., Li, G. Z., and Ning, B. Q. (2019). Possible evidence for small-scale wave seeding of equatorial plasma bubbles. Adv. Space Res., 63(11), 3612-3620. https://doi.org/10.1016/j.asr.2019.02.025

Narayanan, V. L., Taori, A., Patra, A. K., Emperumal, K., and Gurubaran, S. (2012). On the importance of wave-like structures in the occurrence of equatorial plasma bubbles: A case study. J. Geophys. Res., 117(A1), A01306. https://doi.org/10.1029/2011JA017054

Otsuka, Y., Ogawa, T., Saito, A., Tsugawa, T., Fukao, S., and Miyazaki, S. (2002). A new technique for mapping of total electron content using GPS network in Japan. Earth Planets Space, 54(1), 63-70. https://doi.org/10.1186/BF03352422

Patra, A. K., Taori, A., Chaitanya, P. P., and Sripathi, S. (2013). Direct detection of wavelike spatial structure at the bottom of the $F$ region and its role on the formation of equatorial plasma bubble. J. Geophys. Res.: Space Phys., 118(3), 1196-1202. https://doi.org/10.1002/jgra.50148

Ram, S. T., Yamamoto, M., Tsunoda, R. T., Chau, H. D., Hoang, T. L., Damtie, B., Wassaie, M., Yatini, C. Y., Manik, T., and Tsugawa, T. (2014). Characteristics of large-scale wave structure observed from African and Southeast Asian longitudinal sectors. J. Geophys. Res.: Space Phys., 119(3), 2288-2297. https://doi.org/10.1002/2013JA019712

Röttger, J. (1973). Wave-like structures of large-scale equatorial spread- $F$ irregularities. J. Atmos. Terr. Phys., 35(6), 1195-1206. https://doi.org/10.1016/0021-9169(73)90016-0

Saito, S., and Maruyama, T. (2007). Large-scale longitudinal variation in ionospheric height and equatorial spread $F$ occurrences observed by ionosondes. Geophys. Res. Lett., 34(16), L16109.

https://doi.org/10.1029/2007GL030618

Takahashi, H., Wrasse, C. M., Denardini, C. M., Pádua, M. B., de Paula, E. R., Costa,
S. M. A., Otsuka, Y., Shiokawa, K., Monico, J. F. G., ... Sant'Anna, N. (2016). Ionospheric TEC weather map over South America. Space Wea., 14(11), 937-949. https://doi.org/10.1002/2016SW001474

Takahashi, H., Wrasse, C. M., Figueiredo, C. A. O. B., Barros, D. Abdu, M. A., Otsuka, Y., and Shiokawa, K. (2018). Equatorial plasma bubble seeding by MSTIDs in the ionosphere. Progress in Earth and Planetary Science, 5(1), 32. https://doi.org/10.1186/s40645-018-0189-2

Takahashi, H., Wrasse, C. M., Figueiredo, C. A. O. B., Barros, D., Paulino, I., Essien, P., Abdu, M. A., Otsuka, Y., and Shiokawa, K. (2020). Equatorial plasma bubble occurrence under propagation of MSTID and MLT gravity waves. J. Geophys. Res.: Space Phys., 125(9), e2019JA027566. https://doi.org/10.1029/2019JA027566

Thampi, S. V., Yamamoto, M., Tsunoda, R. T., Otsuka, Y., Tsugawa, T., Uemoto, J., and Ishii, M. (2009). First observations of large-scale wave structure and equatorial spread $\mathrm{F}$ using CERTO radio beacon on the C/NOFS satellite. Geophys. Res. Lett., 36(18), L18111. https://doi.org/10.1029/2009GL039887

Tsunoda, R. T., and White, B. R. (1981). On the generation and growth of equatorial backscatter plumes-1. Wave structure in the bottomside $F$ layer. J. Geophys. Res., 86(A5), 3610-3616. https://doi.org/10.1029/JA086iA05p03610

Tsunoda, R. T. (2005). On the enigma of day-to-day variability in equatorial spread F. Geophys. Res. Lett., 32(8), L08103. https://doi.org/10.1029/2005GL022512

Tsunoda, R. T. (2015). Upwelling: a unit of disturbance in equatorial spread $F$. Prog. Earth Planet. Sci., 2(1), 9. https://doi.org/10.1186/s40645-015-0038-5

Tsunoda, R. T., Saito, S., and Nguyen, T. T. (2018). Post-sunset rise of equatorial F layer-or upwelling growth?. Prog. Earth Planet. Sci., 5(1), 22. https://doi.org/10.1186/s40645-018-0179-4

Vadas, S. L., Taylor, M. J., Pautet, P. D., Stamus, P. A., Fritts, D. C., Liu, H. L., São Sabbas, F. T., Rampinelli, V. T., Batista, P., and Takahashi, H. (2009). Convection: the likely source of the medium-scale gravity waves observed in the $\mathrm{OH}$ airglow layer near Brasilia, Brazil, during the SpreadFEx campaign. Ann. Geophys., 27(1), 231-259. https://doi.org/10.5194/angeo-27-231-2009 